\title{
CAE Supported Improvement of Chain Casting of Rip-Saw for Woodworking
}

\author{
Wei-Long Chen, Cheng-Chi Chang, Chen-Yu Tsai, and Fang-Lin Chao
}

\begin{abstract}
The woodworking rip sawing is a machine used for wood preparation. To increase the production rate of wood stock preparation, the sawing speed is of particular importance. The challenge not only comes from a lack of a deeper understanding of how molten alloys fill the mold cavity and form defects but also from improper preliminary part design. This study adjusts the chain design by casting analysis. After the designer added support ribs on the bottom surface and filled in gaps on the edges, the chain piece demonstrated a proportional shrinkage and reduced the strain. Saw blade structural improvement resulted a greater solidification stress, irregular geometric changes after de-moulding. The CAE helps to improve the flatness of the chain and the efficiency of the machine tooling.
\end{abstract}

Index Terms - Casting, CAE, rip-saw, chain.

\section{INTRODUCTION}

In the processing of the logs, the logs are first to cut in the longitudinal direction into plates of different widths and thicknesses (first stock preparation). The huge volume preparation requires large-scale equipment with limited stuff. Rip-saw for woodworking provides both linked chain with no running gap and safety protection [1]. This feature prevents the danger of hand clamping. The pressurized plate holds the workpiece firmly for maximum cutting stability. After cutting into plates of different thicknesses and widths, the wood can be easily transported.

\section{A. Secondary Stock Preparation}

The secondary cutting processing of wood intended to achieve the quality and size specifications. A plurality of saws is used to cut a solid thick sheet to a specific width. For the production of planned flats or plywood, multiple sewing machines dominate. Removable multi-disc saws insertion can accommodate particular widths of applications through optimization techniques (Fig. 1). Multiple saws are important for secondary stock preparation in wood processing.

\section{B. Feeding System}

The feed system is also the key to secondary stock processing. The motor drives the wheel to run the track in the workbench. The wood is placed in the feed port and clamped by the pressing wheel and the crawler belt, and then the main shaft saw blade cuts the board. From the rip saw, the cut board components pass through the free-standing pinch roll

Manuscript received March 7, 2019; revised June 12, 2019.

The authors are with the Department of Industrial Design, Chaoyang University of Technology, Taichung, 436, Taiwan (e-mail weichen@gmail.com). assembly. From the pinch roll assembly, the wood components received at the exit [2]. An adjustable device for feeding workpieces of different thicknesses past a rip saw for cutting purposes. A guide rail is attached to the adjustable fence on the saw table. An engaging and moving member slide along the guide rail for moving the work into cutting engagement [3]. This stage determines the accuracy and quality of wood cutting. If the chain is poorly manufactured, it causes tail flicking on the surface. Some noticeable saw marks results in poor quality through this drifting during sawing (Fig. 2).

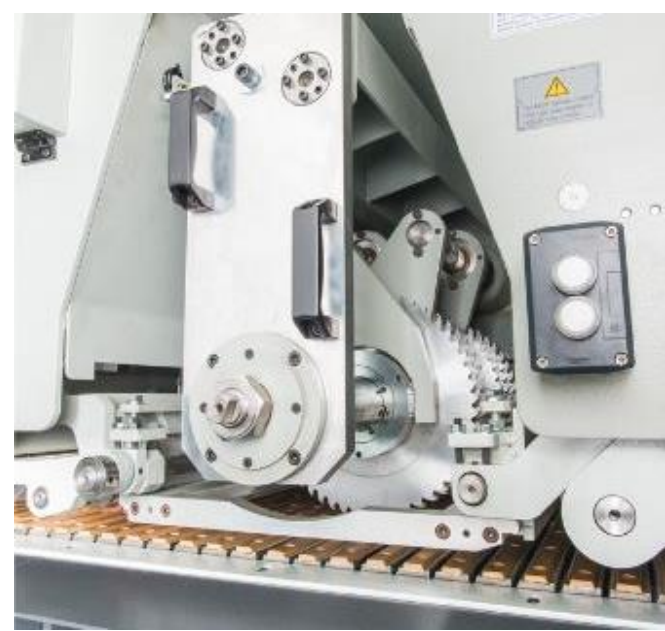

Fig. 1. Buffing wheel and track for holding a log [1].

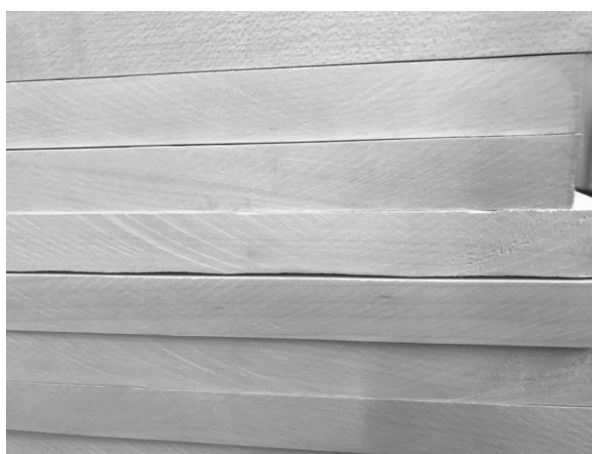

Fig. 2. Drifting in the sawing process creates obvious saw marks.

\section{CAE Simulation AND DESIGN Process}

Improving part manufacturability is important for both the part and mold-design engineer. The previous machine was investigated to reveal the major causes of those defects (Fig. $2)$. The chain piece which holding wood is one of the predominant causes of obvious saw marks. If the flatness of the chain piece is not good, it induced up and down shaking during the movement. This study focused on improvement casting quality of chain piece. 
When the series of chain pieces move forward, part of the chain was hanging down for facilitating the complete cutting of the circular saw into the wooden strip - the chain pulled by the adjacent blocks while the chain hangs down. The pulling between adjacent sections of the chain may cause up and down shaking, which affects the effectiveness of the cutting, this phenomenon will discuss in the future.

CAE supported design flow can identify which design features and process variables are essential and should be modified to prevent the occurrence of defects (Fig. 3). A systematic approach can make a quantitative prediction of casting defects efficiently. When defects can be quantitatively measured and identified in simulation, one can change design and process variables at an early stage of the design process.

We first used CATIA to establish a digital model of the chain piece and simulate the temperature and stress field in the casting process through ProCAST. The casting process is analyzed to undergo shrinkage to maintain the quality of the castings. Several simulation models have been developed to assist in evaluating manufacturing pitfall. For specific design simulation and verification work, this integrated environment provides engineers with an effective strategy of re-design. A simulation model [4] produced by an object-oriented procedure which makes the conversion of a real wood products manufacturing system to a computer model less complicated [5], [6].

An appropriate part modification that compromises between design and manufacture can resolve this problem before they become irreversible. Stress discontinuous edges help predict the possible pitfall of the chain piece. The design process helps the engineer found the practical way to maintain a stable operation which reduces the saw marks on wood and extend the lifetime of the saw blade.

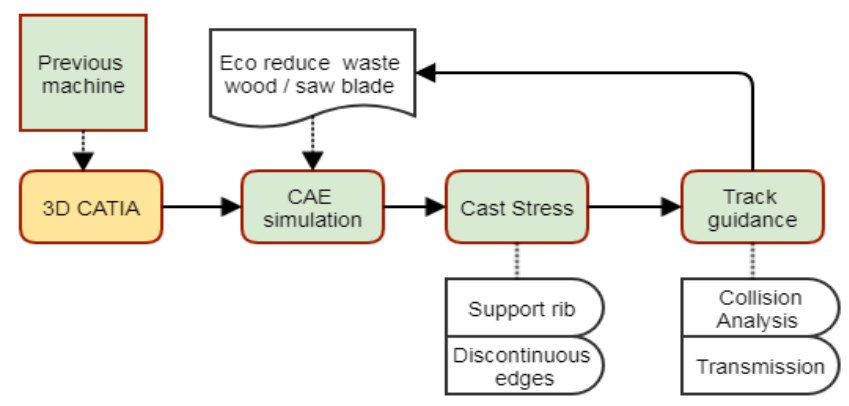

Fig. 3. CAE supported design flow.

\section{GRAVITy CASTING PRocess AND INFLUENCE}

The critical casting process steps are sand casting and solidification. The saw blade requires a high flatness to meet the specification; the parameters during the casting process must be appropriately set.

\section{A. Sand Casting}

We utilize sand casting for the chain piece producing. The molten metal is injected into a hollow mold made of a high-temperature resistant material and solidified to obtain the desired shape. Due to inherent limitations, sand casting has the following disadvantages:

Sand casting can only be poured once; the mould damaged after the cast. The pattern is soft and porous; casting has a rough surface and low dimensional precision. The surface polishing step results in cost increases.

\section{B. Solidification}

The thermal conductivity of sand is small, and the molten metal solidifies slowly during cooling. We assume that the solidification begins after the molten soup fills the cavity. The factors affecting the setting time include the volume and surface area of the casting, the specific heat of the material, the heat transfer coefficient, and the specific heat of the metallization, etc. The solidification time of the cast obtained through the empirical formula "Chvorinov's Rule."

$$
T S T=C_{m}\left(\frac{V}{A}\right)^{n}
$$

TST represents the solidification time, where $V$ is the volume of the casting, $\mathrm{A}$ is the surface area of the casting, the value of the enthalpy $\mathrm{n}$ is usually set to $2 ; C_{m}$ is the coefficient of casting mould. Factors affecting the cooling rate of solidification are the ratio of the volume of the mold to surface area $V / A$, and the capacity of the mould cavity to dissipate $C_{m}$. Solidification analysis need take into account the filling process from the beginning of the casting with the numerical method.

\section{Contraction Stress}

The material shrinks during solidification are essential. The contraction process has three stages. The first stage is the liquid shrinkage at the time of pouring to the time of solidification. The metal gradually solidifies inward from the surface, and the second phase is the solidification shrinkage that occurs during solidification. The third stage is the substantial shrinkage during solidified metal cooling to normal room temperature. The zone of final forms shrinkage porosity due to metal volume changes; this usually occurs in locally thicker areas where feeding is not possible.

Non-uniform shrinkage produces internal stress and produces hot tearing. Controlling the cooling of the mold can reduce the stress; otherwise, it will produce distortion or warpage. Temperatures, stresses, and microstructure lead to a description of a local air gap were calculated during the directional solidification [7]. Environmental impact can be reduced by increasing the use of aluminum alloys. Article [8] investigate and model the heat treatment process for $\mathrm{Al}-\mathrm{Si}$ casting alloys. Three alloys containing $\mathrm{Mg}$ or $\mathrm{Cu}$ were cast using the gradient solidification technique to achieve a low amount of defects. A model for the yield strength of heat-treated Al-Si-Mg casting alloys has developed. The plastic curve of the Al-Si-Cu alloy has a complicated shape which caused by non-coherent precipitates. Several three-dimensional finite element programs such as CAD tools, flow simulation tools (Flow-3D, ProCast) were utilized in the industry [9]-[11]. According to manufacturing variables, CASTS (Computer Aided Solidification Technologies) perform a coupled analysis with the aim of modeling time-dependent air gaps [12].

In actual application, we found that non-uniform gate velocity and geometry dis-continuity caused the separation of metal flow in the forms of droplets and swirling. The increasing of solidification pressure and gate velocity had no 
significant on the temperature distribution in the die with flow length of $300 \mathrm{~mm}$. Therefore, a simplified numerical model can be built [13].

\section{Simulation AND IMPROVED DESIGN OF CASTINGS}

The quantitative analysis is expected to improve the design parameters and reduce the errors. A thermal stresses calculation model for solidification of steel presented in [14]. Creep deformations included stresses release during the early stage of crystallization.

\section{A. Previous Design and Experiment of Saw Piece}

Objects deform due to stress release. We use casting process analysis software ProCAST to simulate the stress changes in the solidification. Areas with substantial stress changes or stress concentration are likely fragile areas. The designer adjust the mould cavity in advance for the structurally weak parts and reinforce the structure with ribs or convex shapes.

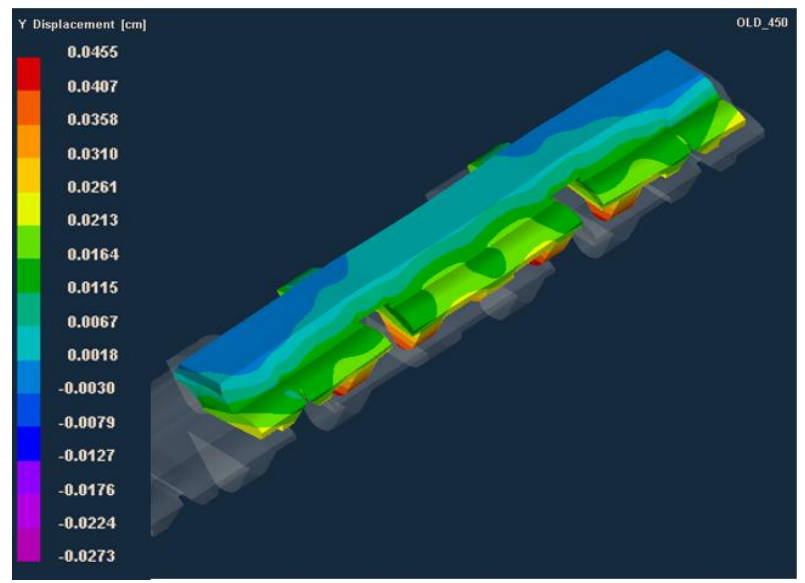

(a)

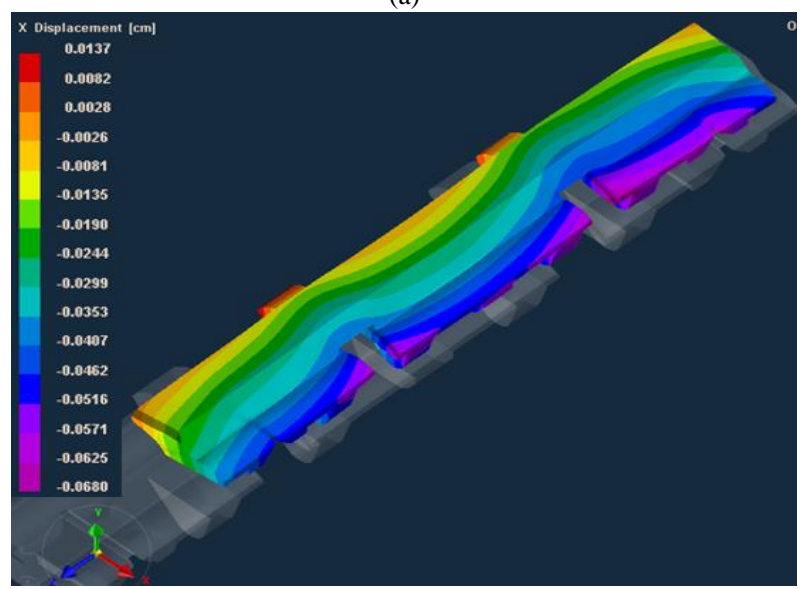

(b)

Fig. 4. Distribution of displacement in the (a) Y direction and (b) X-direction displacement $(\mathrm{cm})$ of the original chain.

From the simulation results (Fig. 4), we found that the original saw piece exhibited a different displacement variation during the solidification stress release. We inferred that the lack of continuity of the long edge of the casting and might contain a gap. The Y-direction deformation is irregular, and it can reasonably conclude that the saw piece needs support ribs and reduce the discontinuity of the edges. The analysis results compared with samples. As indicated in Fig. 5, the deformations caused by shrinkage due to metal volume changes were found especially on edge and thicker regions.

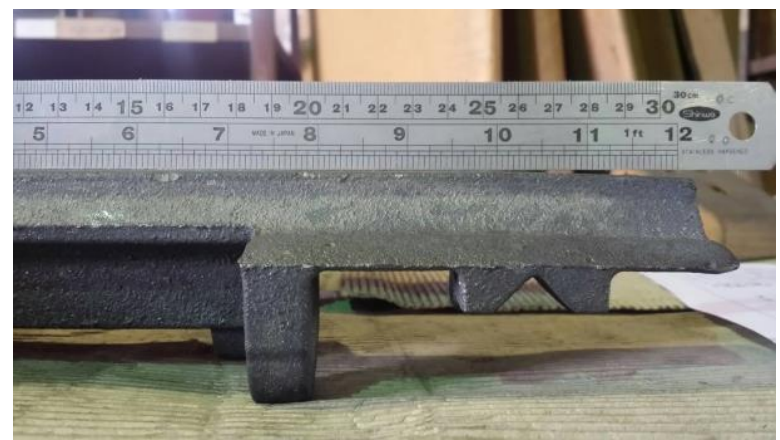

Fig. 5. Working samples of the sand casting.

\section{B. Improved Design to Reduce Warpage}

Based on the stress distribution, a rib structure was added to enhance overall flatness. The rib placed on the bottom surface of the mold and filled in gaps that may appear on the edges. The thickness of the fixture was reduced to minimize the dis-continuous on the edges. Fig. 6 shows the geometric shape of both previous and re-design chain piece.

The analysis of the improved casting solidification and the stress changes are shown in Fig. 7. We found that the enhanced saw piece has a proportional shrinkage during the crystallization, so the stress is released, and the displacement is under controlled.

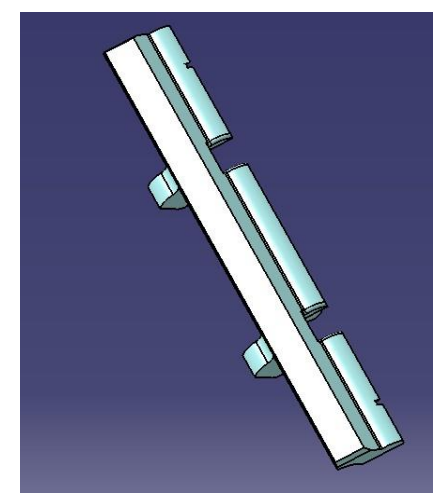

(a)

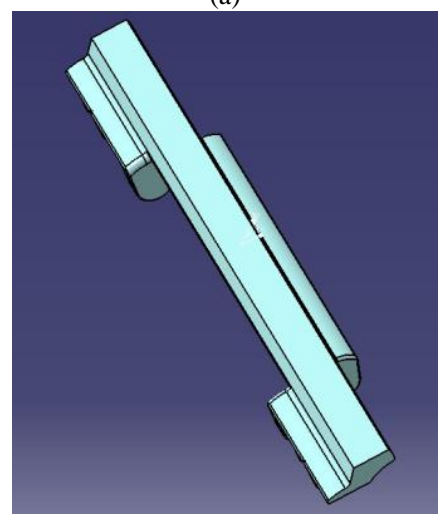

(b)

Fig. 6. The geometric form of both (a) previous design and (b) re-design.

Table I Compare the stress range of previous design and the re-design. The stress range and overall shrinkage (Fig. 7) of re-design are more extensive than the last model. Although the displacement and shrinkage amount are relatively large, the refined cast product exhibits uniform shrinkage. Therefore, 
the entire cast body is not warped or twisted after being cooled and formed. We can see from Fig. 8; it has been reasonably flat on the working plane of the chain piece. The improved design reduces unnecessary secondary processing and reduces material consumption and costs.

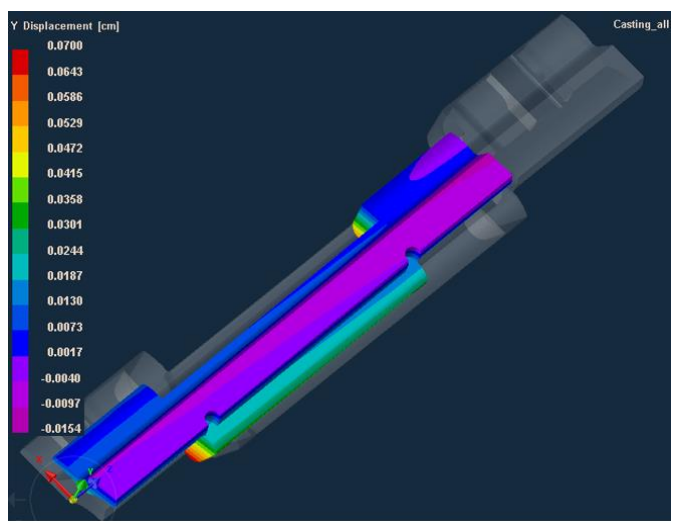

(a)

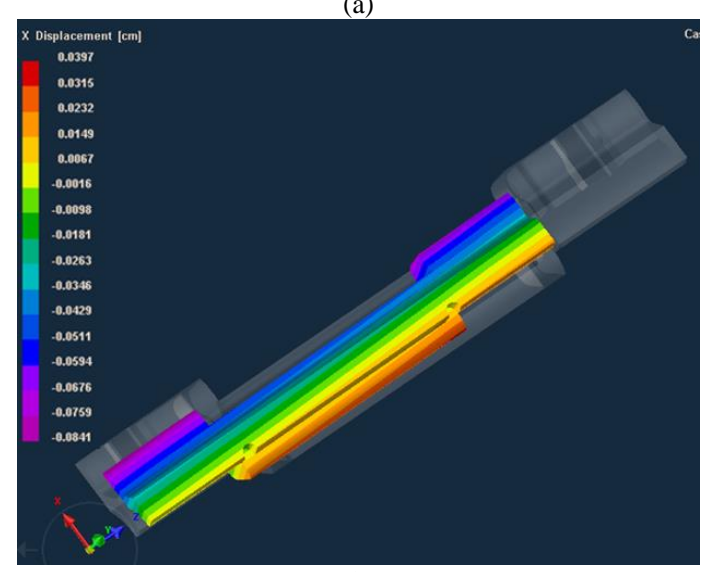

(b)

Fig. 7. Analysis of displacement change in (a) Y-direction, and (b) $\mathrm{X}$-direction of modified saw piece.

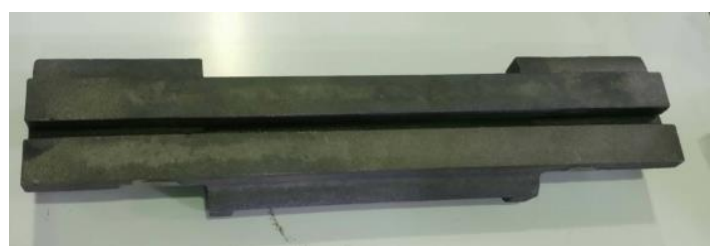

Fig. 8. The defects reducted of saw piece assembly.

TABLE I: DiSPLACEMENT RANGE

\begin{tabular}{l|l|l|l}
\multicolumn{5}{c}{ TABLE I: DISPLACEMENT RANGE } \\
\hline & & $Y(\mathrm{~cm})$ & $X(\mathrm{~cm})$ \\
\hline previous & Max & 0.0466 & 0.0137 \\
& Min & -0.0273 & -0.0680 \\
\hline Re-design & Max & 0.0700 & 0.0397 \\
& Min & -0.0154 & -0.0841 \\
\hline
\end{tabular}

The ribs on the bottom surface filled in gaps on the edges, the saw piece demonstrated a proportional shrinkage which reduced warpage (Fig. 8). The parts can assembly with high precession and low spacing with adjacent parts. The reduction of defects of saw piece assembly will alleviate the problem in wood processing; it also enhance the flatness of the wood surface.

\section{CONCLUSION}

The reduction of defects of saw piece assembly will alleviate the problem in wood processing; it will also enhance the flatness of the wood surface. The main improvements are the structural re-design of the chain piece. Shoddy construction resulted in greater solidification stress of the casting. After the designer added support ribs on the bottom surface and filled in gaps on the edges, the saw piece demonstrated a proportional shrinkage. Minor modification in the gating system and part features produced continuous and uniform flow pattern. The modified model does reduce the occurrence of the defects.

The engineer hopes further increase the speed of wood preparation and sawing. At this situation, vibration control is important to improve the efficiency of machining. Designers have to avoid the chain piece accidentally picked up during track feeding. This kinematic reactions of chain elements will be studied in future.

\section{REFERENCES}

[1] OAV Equipment. [Online]. Available: https://www.oavequipment.com/zh-tw/product-294920/

[2] T. W. Hahn, "Automated multiple rip saw feeding apparatus," U.S. Patent 4,945,797, Buss Automation Inc, 1990.

[3] L. R. Livick and R. Lester, "Adjustable device for feeding workpieces of different thicknesses past a rip saw for cutting purposes," U.S. Patent 4,026,173, 1977.

[4] D. E. Kline, J. K. Wiedenbeck, and P. A. Araman, "Management of wood products manufacturing using simulation/animation," Forest Products Journal, vol. 42, no.2, pp.45-52, 1992.

[5] P. A. Araman, "Use of computer simulation in designing and evaluating a proposed rough mill for furniture interior parts," USDA Forest Serv. Res. Pap. NE-361, USDA Forest Sew., Northeastern Forest Expt. Sta., Upper Darby, Pa, 1977.

[6] D. J. Bonham, R. Hall, P. Egan, and S. Lane, "Simulation of small-log Canadian softwood sawmills using discrete-event simulation and expert systems," in Proc. CSME Mechanical Engineering Forum, 1990.

[7] M. Fackeldey, A. Ludwig, and P. R. Sahm, "Coupled modelling of the solidification process predicting temperatures, stresses, and microstructures," Computational Materials Science, vol. 7, no. 1-2, pp. 194-199, 1996.

[8] S. Saxena, C. H. Tyagi, and S. Kumar, "Heat treatment of Al-Si-Cu-Mg casting alloys for the manufacturing of light weight machines/ vehicle parts with increased strength," International Journal of Mechanical Engineering and Robotics Research, vol. 3, no. 3, pp. 706-715, 2014.

[9] A. Sholapurwalla, "Virtual casting: Die casting process simulation," Die Casting Engineer, vol. 4, no. 2, pp. 58-62, 2002.

[10] S. Mahaney and C.-W.Kim, "Modeling of the die cast process: a finite element method approach," Die Casting Engineer; vol. 40, no.64, p. 3, Nov.-Dec. 1996.

[11] M. R. Barone and D. A. Caulk, "Analysis of liquid metal flow in die casting," International Journal of Engineering Science, vol. 38, pp. 1279-1302, 2000

[12] Y. Wang, B. Sun, Q. Wang, Y. Zhu, and W. Ding, “An understanding of the hot tearing mechanism in AZ91 magnesium alloy," Materials Letters, vol. 53, no. 1-2, pp. 35-39, 2002.

[13] W.-L. Chen, "A development of virtual manufacturing system for magnesium high pressure die casting processes," in Proc. ASME 2003 International Mechanical Engineering Congress and Exposition, American Society of Mechanical Engineers, 2003.

[14] J. O. Kristiansson, "Thermal stresses in the early stage of solidification of steel," Journal of Thermal Stresses, vol. 5, no. 3-4, pp. 315-330, 1982 .

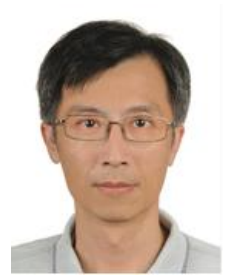

Wei-Long Chen received the Ph.D. degree in aerospace engineering from the University of Oklahoma. He was a researcher of MSC Software. He also served as a consultant in several companies such as Pro-Iroda, Grand Mate and Aerospace Institute.

He joined National Center for High-Performance Computing, Hsinchu, Taiwan. Since September 1999, he has been an associate professor with the Department of Industrial Design at Chaoyang University of Technology, Taichung, Taiwan. His research interests include CAE and 
product development.

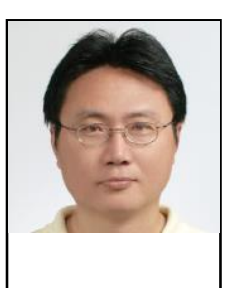

Fang-Lin Chao received the Ph.D. degree in electrical engineering from National Taiwan University. He joined the Electronic Research and Service Organization, Industrial Technology Research Institute, Hsinchu, Taiwan, in 1982. In 1994, he was an associate professor with Da-Yeh Institute of Technology. Since September 2004, he has been an associate professor with the Department of Industrial Design at Chaoyang University of Technology, Taichung, Taiwan. His research interests include eco-design and design integration in product development.

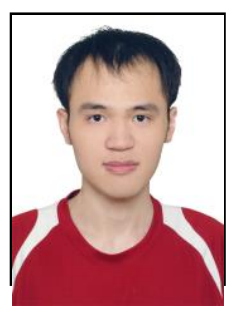

Cheng-Chi Chang graduated from the Department of Industrial Design at the Chaoyang University of Technology. He is a design assistant in the R\&D Department of Woodworking Machinery Company. $\mathrm{He}$ is a master student supervised by Prof. Chen. His research interests include machine design, CAD and product development.
Chen-Yu Tsai graduated from the Department of Industrial Design at Chaoyang University of Technology, Taiwan in 2017. He wins the grand prize of the design competition. Currently, he is a master student supervised by Prof. Chen. His research interests include creative-design, $\mathrm{CAD}$ and product development. 